\title{
Metabolic and Cardiovascular Effects of Ghrelin
}

\section{Manfredi Tesauro, ${ }^{1}$ Francesca Schinzari, ${ }^{2}$ Miriam Caramanti, ${ }^{1}$ Renato Lauro, ${ }^{1}$ and Carmine Cardillo ${ }^{2}$}

\author{
${ }^{1}$ Department of Medicina Interna, Università di Tor Vergata, 00133 Rome, Italy \\ ${ }^{2}$ Istituto di Patologia Speciale Medica e Semeiotica Medica, Università Cattolica del Sacro Cuore, 00168 Roma, Italy
}

Correspondence should be addressed to Carmine Cardillo, carmine.cardillo@rm.unicatt.it

Received 19 November 2009; Accepted 16 January 2010

Academic Editor: Alessandro Laviano

Copyright (C) 2010 Manfredi Tesauro et al. This is an open access article distributed under the Creative Commons Attribution License, which permits unrestricted use, distribution, and reproduction in any medium, provided the original work is properly cited.

\begin{abstract}
Ghrelin, an endogenous ligand for the growth hormone secretagogue receptor, is synthesized as a preprohormone and then proteolytically processed to yield a 28 -amino acid peptide. This peptide was originally reported to induce growth hormone release; large evidence, however, has indicated many other physiological activities of ghrelin, including regulation of food intake and energy balance, as well as of lipid and glucose metabolism. Ghrelin receptors have been detected in the hypothalamus and the pituitary, but also in the cardiovascular system, where ghrelin exerts beneficial hemodynamic activities. Ghrelin administration acutely improves endothelial dysfunction by increasing nitric oxide bioavailability and normalizes the altered balance between endothelin-1 and nitric oxide within the vasculature of patients with metabolic syndrome. Other cardiovascular effects of ghrelin include improvement of left ventricular contractility and cardiac output, as well as reduction of arterial pressure and systemic vascular resistance. In addition, antinflammatory and antiapoptotic actions of ghrelin have been reported both in vivo and in vitro. This review summarizes the most recent findings on the metabolic and cardiovascular effects of ghrelin through GH-dependent and -independent mechanisms and the possible role of ghrelin as a therapeutic molecule for treating cardiovascular diseases.
\end{abstract}

\section{Introduction}

Ghrelin, a 28-amino-acid peptide hormone mainly secreted by the X/A-like cells in the oxyntic mucosa of the stomach, has been discovered as the endogenous ligand of the orphan receptor growth hormone secretagogues 1a (GHS-R1a) [1]. In addition to its marked growth hormone $(\mathrm{GH})$ releasing activity, ghrelin stimulates food intake and is involved in the regulation of energy homeostasis [2]. Furthermore, ghrelin has a variety of cardiovascular activities, including cardioprotective effects against ischemia, enhancement of vasodilation, cardiotropic effects, and regulation of blood pressure [3-5].

Human ghrelin gene is located on chromosome 3 and consists of 4 exons and 3 introns that encode a 117-aminoacid peptide, pre-proghrelin, that is cleaved into the mature 28 -amino-acid form $(3.3 \mathrm{kDa})$ secreted into the blood stream $[6,7]$. Two major forms of ghrelin are found in tissues and plasma: n-octanoyl-modified ghrelin and des-acyl ghrelin [7]; ghrelin is the first known secreted bioactive peptide in mammals modified by an acyl acid on its third serine residues through the recently discovered enzyme ghrelin O-acyl transferase (GOAT) [8-10]. This postranslational modification is essential for binding to the GHS-R 1a and for several ghrelin biological activities, including the GH-releasing capacity and the actions on the endocrine axis, on energy balance and glucose homeostasis [3]. Nonacylated ghrelin, which represents the most abundant form of circulating ghrelin (80\%-90\%), has been found to be devoid of GH releasing capacity $[1,11,12]$, but exerts a variety of physiological activity in the cardiovascular system as well as in lipid and glucose metabolism $[13,14]$.

Central and peripheral administration of des-acyl ghrelin significantly decreases food intake and decreases gastric emptying in food-deprived mice [15]. In another study, Chen et al. confirmed that des-acyl ghrelin decreases food intake in mice and showed that ghrelin disrupts the fasted motor activity of the antrum in freely moving conscious rats [16]. Moreover, centrally administrated des-acyl ghrelin increases feeding through activation of the orexin 
pathway and may act in hypothalamic feeding regulation [17].

Ghrelin plasma levels are mainly regulated by nutritional and metabolic factors; in fact they are increased by energy restriction (such as malnutrition, anorexia nervosa, and cachexia) and decreased by food intake and overfeeding [18]. These notions are in agreement with several studies showing reduced circulating ghrelin in patients with obesity and metabolic syndrome $[19,20]$. Furthermore, ghrelin circulating levels increase in obese subjects when they lose weight $[21,22]$.

While all forms of human obesity have inappropriately low ghrelin levels, the only exception is the Prader-Willy syndrome, a complex genetic disorder characterized by mental retardation, hyperphagia, short height due to GH deficiency, and muscular hypotony [23]. In these patients, excessive appetite causes progressive obesity, which is surprisingly associated with high ghrelin levels in the same range of patients with anorexia nervosa.

In a recent study, Kirchner et al. suggested that the ghrelin/GOAT system acts as a lipid nutrient sensor that informs the central nervous system on the availability of substrates, rather than a meal initiation factor in reply to fasting [10]. It has also been reported that ghrelin is not inhibited by gastric distension due to water intake but is reduced by glucose administration [24]. Moreover, intravenous glucose loads inhibit ghrelin secretion, whereas protein intake seems to increase or to not modify ghrelin levels [25]. By contrast, constant infusion of lipids does not influence ghrelin levels, while oral administration of fats reduces them, even though not as much as glucose administration [26]. Moreover, it has been demonstrated that ghrelin induces an increase in glucose levels and this effect could be related to activation of glycogenolysis, increased liver gluconeogenesis, or stimulation of catecholamine release [27-30].

A negative association has been shown between ghrelin and insulin secretion [31], but the exact mechanisms by which insulin regulates ghrelin secretion need further studies. Hyperinsulinemia, however, has been suggested to act as a feedback mechanism to suppress ghrelin secretion, because several studies have reported reduced plasma ghrelin in association with different insulin resistance states, including hypertension, type 2 diabetes, or polycystic ovary syndrome [32].

A positive correlation between ghrelin and high-density lipoprotein (HDL) cholesterol concentration has also been observed $[33,34]$ and, in another study, Park et al. have shown that fasting plasma ghrelin levels are negatively correlated with triglycerides and positively correlated with HDL cholesterol in boys but not in girls; the mechanism underlying this sex difference, however, is not well established [35].

Ghrelin secretion seems to be under cholinergic control, since ghrelin levels are raised by cholinergic agonists and reduced by cholinergic antagonists [14]. In addition, Williams et al. showed that fast-induced rise of ghrelin levels is prevented by vagotomy and is reduced by atropine in rats [36]. Interestingly, ghrelin stimulates the differentiation of preadipocytes and antagonizes lipolysis in vitro [37] and promotes bone marrow adipogenesis in vivo [38]. Chronic ghrelin administration increases body weight, adiposity, and the expression of uncoupling protein (UCP) mRNA in brown and white adipose tissue in mice [39].

\section{Tissue Distribution of Ghrelin and Ghrelin Receptor}

Ghrelin is predominantly produced by the stomach, but it is also widely expressed in different tissues, such as the hypothalamus, pituitary gland, small and large intestine, placenta, pancreas, kidney, testes, ovary, and lymphocytes [40]. Ghrelin has also been found in several human neoplastic tissues and related cancer cells such as gastric and intestinal carcinoids, lymphomas and thyroid, breast, liver, lung, and prostate carcinomas $[41,42]$.

The ghrelin receptor (GHS-R) is a typical G-proteincoupled, seven transmembrane domain receptor. The gene of the human GHS-R 1a is located on chromosome 3q26.2 [43] and encodes for two different splice forms of the human GHS-R: GHS-R 1a, which binds ghrelin and leads to intracellular calcium mobilization, and GHS-R $1 \mathrm{~b}$, which is not able to bind ghrelin [44].

The GHS-R 1a is particularly concentrated in the hypothalamic-pituitary unit but is also present in other areas of the central nervous system and in several endocrine and nonendocrine tissues, including pancreas, lung, liver, kidney, small and large intestines, myocardium, spleen, ovary, testis, adrenal, adipose tissue, stomach, and the neuronal cells of the gut, both in animals and humans [45].

Also the GHS-R $1 \mathrm{~b}$ has been found in many peripheral organs, including immune cells, skin, myocardium, pituitary, thyroid, pancreas, ileum, colon, liver, breast, spleen, duodenum, placenta, lung, adrenal, buccal mucosa, stomach, lymphonode, atrium, lymphocytes, and kidney [46]. Interestingly, both GHS-R subtypes have been found in tumoral tissues from organs that do not express these receptors in physiological conditions, for example, the breast [47].

In humans, the mRNA encoding GHS-R1a is detected in the cardiovascular system, but its expression in this system is much lower than in the pituitary [46]. Other authors have shown that human endothelial cells express ghrelin and the presence of ghrelin receptor has been reported in human endothelial cells, vascular smooth muscle cells, and the left ventricle [48]. Also GHS-R1b transcripts are highly expressed in human myocardium, but their physiological function is still unknown [46].

Analyzing ghrelin binding sites in the cardiovascular system, Katugampola et al. demonstrated a higher density of receptors in the myocardium of the right atrium than in the left ventricle, whereas aorta and pulmonary artery have more receptors than saphenous vein or coronary artery (Table 1). Moreover, the same investigators noticed a change in receptors density as a consequence of vascular diseases, with upregulation of ghrelin in vessels with advanced intimal thickening [49]. Binding studies have evidenced the existence of a subtype of ghrelin receptor distinct from 
GHS-R 1a, with the same binding affinity both for acylated ghrelin and nonacylated ghrelin, in $\mathrm{H} 9 \mathrm{C} 2$ cardiomyocites and endothelial cells [50].

\section{Cardiovascular Effects of Ghrelin}

Studies both in animal models and humans have shown beneficial effects of ghrelin in the cardiovascular system to support the wide expression of its receptors in cardiovascular tissues (Figure 1).

In animal models, ghrelin has been found to improve cardiac contractility in pathological conditions, to reduce the infarct size and to attenuate the reduction in left ventricular function induced by ischemia-reperfusion [51]. In particular, Frascarelli et al. have found that ghrelin administration significantly reduces the infarct size, as estimated by triphenyltetrazolium chloride staining, in a rat ischaemiareperfusion model $[52,53]$. Furthermore, in a group of rats following myocardial infarction, ghrelin administration has shown to increase body weight, cardiac output, and diastolic thickness of the noninfarcted posterior wall, as well as to inhibit left ventricular enlargement [53]. In animal models of heart failure, ghrelin administration improves cardiac contractility and attenuates the development of cardiac cachexia $[52,53]$.

In normal subjects, intravenous or subcutaneous ghrelin injection increases cardiac output, improves cardiac contractility, and causes a significant decrease in mean arterial pressure, without changing heart rate [54]. In addition to this, abundant evidence demonstrates a therapeutic effect of ghrelin in patients with heart failure. Thus, ghrelin has been reported to improve left-ventricular function and to attenuate left-ventricular remodelling in patients with chronic heart failure; in addition, acute ghrelin administration has shown to decrease systemic vascular resistances and increase cardiac output, cardiac index, and stroke volume index in patients with chronic heart failure [55]. The same authors have noticed that treatment with ghrelin for three weeks increases body weight, lean body mass, and muscle strength [55]. These results suggest that ghrelin could improve muscle wasting in patients with chronic heart failure and cardiac cachexia, a severe catabolic state characterized by weight loss and muscle wasting, resistant to long-term treatment with nutritional supplements.

In keeping with these findings, other studies have emphasized that ghrelin might have a role in patients with end-stage heart failure and cardiac cachexia, by improving cardiac function and increasing appetite [56, 57]. Ghrelin intravenous administration has therefore been proposed as adjuvant therapy in heart failure, due to its capacity to lead to a gain in left ventricular mass, to increase left ventricular ejection fraction, and to decrease left ventricular end-systolic volume [55].

A negative correlation has been noticed between ghrelin plasma levels and blood pressure, which might suggest that ghrelin is also involved in the sympathetic regulation. In fact, ghrelin seems to suppress sympathetic activity and to decrease blood pressure through mechanisms involving the central nervous system [58]. This hypothesis is supported by studies showing that ghrelin administration significantly decreases plasma norepinephrine levels and the ratio between low-to-high frequency spectra of heart rate variability in rats with myocardial infarction [59]. The reduction in peripheral resistance following ghrelin intravenous infusion results in a decrease in blood pressure levels in humans, even though supraphysiological hormone levels are required to produce this effect $[54,60]$. Other mechanisms have been proposed to explain the reduction in blood pressure after ghrelin administration, including vasodilation via endothelium activation or a direct effect on vascular smooth muscle cells $[27,61]$.

In vitro studies suggested that, in human mammary artery, ghrelin causes vasorelaxation by antagonizing the endothelin-induced contraction [61]. We have demonstrated that ghrelin reverses endothelial dysfunction in patients with metabolic syndrome by increasing nitric oxide (NO) bioavailability [62]. We have also reported the molecular vascular actions of ghrelin, which stimulates the production of NO using a signaling pathway involving GHS-R 1a, PI 3 kinase, AKT, and eNOS [63]. More recently, we have extended our knowledge regarding the favorable endothelial actions of ghrelin by demonstrating that this peptide normalizes the altered NO/ET-1 balance within the vasculature of patients with metabolic syndrome, thus suggesting an important role of ghrelin in the regulation of vascular homeostasis [64].

\section{Antiapoptotic Effects of Ghrelin in the Cardiovascular System}

Ghrelin has also shown to act as an antiapoptotic peptide in the cardiovascular system.

In vitro studies suggest that ghrelin stimulates $\mathrm{H} 9 \mathrm{c} 2 \mathrm{car}-$ diomyocyte proliferation and reduces doxorubicin-induced apoptosis in cardiomyocytes and endothelial cells $[50,65]$. Iglesias et al. found that ghrelin is synthesized and secreted by isolated murine and human cardiomyocytes and is able to prevent apoptosis induced by treatment with the apoptosisinducer cytosine arabinoside (AraC) in mouse adult cardyomyocites cell line HL-1 [66]. Moreover, ghrelin treatment of primary cardiomyocytes prevents apoptosis stimulated by anti-FAS agonist antibodies. In addition, ghrelin stimulates tyrosine phosphorylation and activates ERK-1/2 and Akt in cardiomyocytes and endothelial cells; the activation of these two pathways is required for the antiapoptotic effect of ghrelin [50]. Furthermore, Isgaard et al. have found that ghrelin is also able to stimulate proliferation of $\mathrm{H} 9 \mathrm{c} 2$ cardiomyocytes (a cardiac cell line that does not express the ghrelin receptor) in a dose-dependent and specific manner by increasing thymidine incorporation; however, they have reported the presence of alternative ghrelin binding sites on cardiomyocytes cell membranes in the absence of GHS-R 1a [67]. In another study, Kola et al. have proposed that ghrelin might modulate intracellular energy balance in a cell specific manner: ghrelin would be able to stimulate the $5^{\prime}$ AMP activated protein kinase (AMPK) that has a central role in regulating energy provisions in cells especially during 


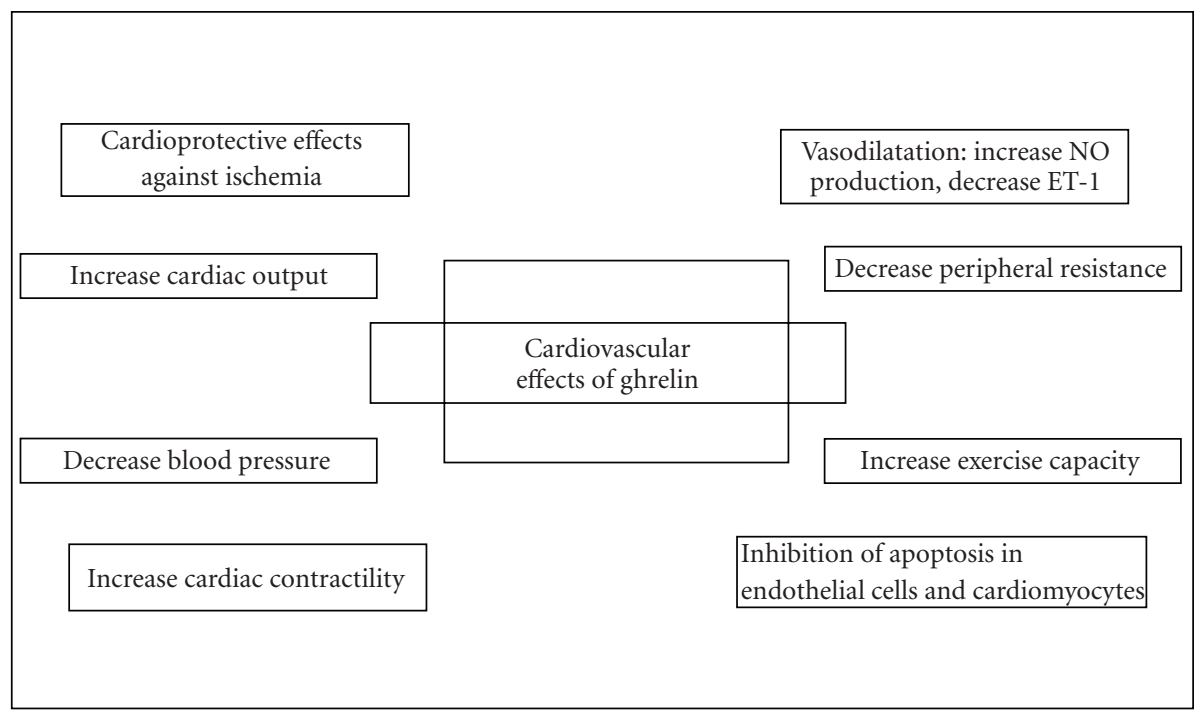

Figure 1: Cardiovascular effects of ghrelin.

TABLE 1: GHS1 receptors in the human cardiovascular system.

Myocardium
Left ventricle
Aortic endothelium
Mammary artery
Coronary artery
Ventricular cardiomyocites
Vascular smooth muscle
Carotid
Saphenous vein

anaerobic conditions [68]. Ghrelin effect on AMPK activity may be involved in the mechanism of cardioprotection from cellular injury and from ischemia-reperfusion damage [60].

\section{Anti-inflammatory Effect of Ghrelin}

Recent findings suggest that ghrelin has potent antiinflammatory effects within the immune system and in human endothelial cells.

Dixit et al. found that ghrelin exerts specific and selective inhibitory effects on the expression of the inflammatory cytokines IL- $1 \beta$, IL-6, and TNF- $\alpha$ [69]. Moreover, T lymphocytes express both ghrelin and the GHS-R and ghrelin secretion is increased when T lymphocytes are activated [69].

Administration of the GHS.1a agonist GHRP-2 results in decreased IL-6 levels and reduced signs of joint inflammation in arthritic rats [70]. Moreover, DeBoer et al. reported a significant decrease in circulating proinflammatory cytokines in ghrelin-treated rats with chronic kidney diseases (CKD); they also observed an increase in the circulating levels of the anti-inflammatory cytokines IL-10 in CKD rats treated with the ghrelin receptor agonist BIM-28125 [71]. In addition, ghrelin has potent anti-inflammatory effects in human endothelial cells, likely mediated by inhibition of NF- $\kappa \mathrm{B}$, and also inhibits inflammatory cytokines produced by endothelial cells in response to LPS [72]. These anti-inflammatory effects of ghrelin suggest a possible modulatory role of the peptide as a novel strategy in several cardiometabolic disorders associated with chronic systemic inflammation.

\section{Conflict of Interest}

The authors declare no conflict of interest.

\section{References}

[1] M. Kojima, H. Hosoda, Y. Date, M. Nakazato, H. Matsuo, and K. Kangawa, "Ghrelin is a growth-hormone-releasing acylated peptide from stomach," Nature, vol. 402, no. 6762, pp. 656660, 1999.

[2] O. Gualillo, F. Lago, J. Gómez-Reino, F. F. Casanueva, and C. Dieguez, "Ghrelin, a widespread hormone: insights into molecular and cellular regulation of its expression and mechanism of action," FEBS Letters, vol. 552, no. 2-3, pp. 105-109, 2003.

[3] A. J. van der Lely, M. Tschöp, M. L. Heiman, and E. Ghigo, "Biological, physiological, pathophysiological, and pharmacological aspects of ghrelin," Endocrine Reviews, vol. 25, no. 3, pp. 426-457, 2004.

[4] E. Ghigo, F. Broglio, E. Arvat, M. Maccario, M. Papotti, and G. Muccioli, "Ghrelin: more than a natural GH secretagogue and/or an orexigenic factor," Clinical Endocrinology, vol. 62, no. 1, pp. 1-17, 2005.

[5] J.-M. Cao, H. Ong, and C. Chen, "Effects of ghrelin and synthetic GH secretagogues on the cardiovascular system," Trends in Endocrinology and Metabolism, vol. 17, no. 1, pp. 13$18,2006$.

[6] M. Kojima, H. Hosoda, H. Matsuo, and K. Kangawa, "Ghrelin: discovery of the natural endogenous ligand for the growth hormone secretagogue receptor," Trends in Endocrinology and Metabolism, vol. 12, no. 3, pp. 118-122, 2001. 
[7] M. P. Wajnrajch, I. S. Ten, J. M. Gertner, and R. L. Leibel, "Genomic organization of the human ghrelin gene," Journal of Endocrine Genetics, vol. 1, no. 4, pp. 231-233, 2000.

[8] J. A. Gutierrez, P. J. Solenberg, D. R. Perkins, et al., "Ghrelin octanoylation mediated by an orphan lipid transferase," Proceedings of the National Academy of Sciences of the United States of America, vol. 105, no. 17, pp. 6320-6325, 2008.

[9] J. Yang, M. S. Brown, G. Liang, N. V. Grishin, and J. L. Goldstein, "Identification of the acyltransferase that octanoylates ghrelin, an appetite-stimulating peptide hormone," Cell, vol. 132, no. 3, pp. 387-396, 2008.

[10] H. Kirchner, J. A. Gutierrez, P. J. Solenberg, et al., "GOAT links dietary lipids with the endocrine control of energy balance," Nature Medicine, vol. 15, no. 7, pp. 741-745, 2009.

[11] M. A. Bednarek, S. D. Feighner, S.-S. Pong, et al., "Structurefunction studies on the new growth hormone-releasing peptide, ghrelin: minimal sequence of ghrelin necessary for activation of growth hormone secretagogue receptor 1a," Journal of Medicinal Chemistry, vol. 43, no. 23, pp. 4370-4376, 2000.

[12] G. Muccioli, M. Papotti, V. Locatelli, E. Ghigo, and R. Deghenghi, "Binding of 125I-labeled ghrelin to membranes from human hypothalamus and pituitary gland," Journal of Endocrinological Investigation, vol. 24, no. 3, pp. RC7-RC9, 2001.

[13] F. Broglio, F. Prodam, E. Me, et al., "Ghrelin: endocrine, metabolic and cardiovascular actions," Journal of Endocrinological Investigation, vol. 28, no. 5, pp. 23-25, 2005.

[14] M. Korbonits, A. P. Goldstone, M. Gueorguiev, and A. B. Grossman, "Ghrelin-a hormone with multiple functions," Frontiers in Neuroendocrinology, vol. 25, no. 1, pp. 27-68, 2004.

[15] A. Asakawa, A. Inui, M. Fujimiya, et al., "Stomach regulates energy balance via acylated ghrelin and desacyl ghrelin," Gut, vol. 54, no. 1, pp. 18-24, 2005.

[16] C.-Y. Chen, A. Inui, A. Asakawa, et al., "Des-acyl ghrelin acts by CRF type 2 receptors to disrupt fasted stomach motility in conscious rats," Gastroenterology, vol. 129, no. 1, pp. 8-25, 2005.

[17] K. Toshinai, H. Yamaguchi, Y. Sun, et al., "Des-acyl ghrelin induces food intake by a mechanism independent of the growth hormone secretagogue receptor," Endocrinology, vol. 147, no. 5, pp. 2306-2314, 2006.

[18] H. Hosoda, M. Kojima, and K. Kangawa, "Ghrelin and the regulation of food intake and energy balance," Molecular Interventions, vol. 2, no. 8, pp. 494-503, 2002.

[19] S. M. Pöykkö, E. Kellokoski, S. Hörkkö, H. Kauma, Y. A. Kesäniemi, and O. Ukkola, "Low plasma ghrelin is associated with insulin resistance, hypertension, and the prevalence of type 2 diabetes," Diabetes, vol. 52, no. 10, pp. 2546-2553, 2003.

[20] T. Shiiya, M. Nakazato, M. Mizuta, et al., "Plasma ghrelin levels in lean and obese humans and the effect of glucose on ghrelin secretion," Journal of Clinical Endocrinology and Metabolism, vol. 87, no. 1, pp. 240-244, 2002.

[21] L. Soriano-Guillén, V. Barrios, Á. Campos-Barros, and J. Argente, "Ghrelin levels in obesity and anorexia nervosa: effect of weight reduction or recuperation," Journal of Pediatrics, vol. 144, no. 1, pp. 36-42, 2004.

[22] D. E. Cummings, D. S. Weigle, R. S. Frayo, et al., "Plasma ghrelin levels after diet-induced weight loss or gastric bypass surgery," New England Journal of Medicine, vol. 346, no. 21, pp. 1623-1630, 2002.

[23] D. E. Cummings, K. Clement, J. Q. Purnell, et al., "Elevated plasma ghrelin levels in Prader-Willi syndrome," Nature Medicine, vol. 8, no. 7, pp. 643-644, 2002.
[24] M. Tschop, D. L. Smiley, and M. L. Heiman, "Ghrelin induces adiposity in rodents,” Nature, vol. 407, no. 6806, pp. 908-913, 2000.

[25] M. Groschl, I. Knerr, H.-G. Topf, P. Schmid, W. Rascher, and M. Rauh, "Endocrine responses to the oral ingestion of a physiological dose of essential amino acids in humans," Journal of Endocrinology, vol. 179, no. 2, pp. 237-244, 2003.

[26] J. Erdmann, F. Lippl, and V. Schusdziarra, "Differential effect of protein and fat on plasma ghrelin levels in man," Regulatory Peptides, vol. 116, no. 1-3, pp. 101-107, 2003.

[27] N. Nagaya, K. Miyatake, M. Uematsu, et al., "Hemodynamic, renal, and hormonal effects of ghrelin infusion in patients with chronic heart failure," Journal of Clinical Endocrinology and Metabolism, vol. 86, no. 12, pp. 5854-5859, 2001.

[28] E. V. Dimaraki and C. A. Jaffe, "Role of endogenous ghrelin in growth hormone secretion, appetite regulation and metabolism," Reviews in Endocrine and Metabolic Disorders, vol. 7, no. 4, pp. 237-249, 2006.

[29] M. Murata, Y. Okimura, K. Iida, et al., "Ghrelin modulates the downstream molecules of insulin signaling in hepatoma cells," Journal of Biological Chemistry, vol. 277, no. 7, pp. 5667-5674, 2002.

[30] F. Broglio, A. Benso, C. Castiglioni, et al., "The endocrine response to ghrelin as a function of gender in humans in young and elderly subjects," Journal of Clinical Endocrinology and Metabolism, vol. 88, no. 4, pp. 1537-1542, 2003.

[31] M. Tschöp, C. Weyer, P. A. Tataranni, V. Devanarayan, E. Ravussin, and M. L. Heiman, "Circulating ghrelin levels are decreased in human obesity," Diabetes, vol. 50, no. 4, pp. 707709, 2001.

[32] U. Pagotto, A. Gambineri, V. Vicennati, M. L. Heiman, M. Tschöp, and R. Pasquali, "Plasma ghrelin, obesity, and the polycystic ovary syndrome: correlation with insulin resistance and androgen levels," Journal of Clinical Endocrinology and Metabolism, vol. 87, no. 12, pp. 5625-5629, 2002.

[33] B. Fagerberg, L. M. Hultén, and J. Hulthe, "Plasma ghrelin, body fat, insulin resistance, and smoking in clinically healthy men: the atherosclerosis and insulin resistance study," Metabolism, vol. 52, no. 11, pp. 1460-1463, 2003.

[34] C. Langenberg, J. Bergstrom, G. A. Laughlin, and E. BarrettConnor, "Ghrelin and the metabolic syndrome in older adults," Journal of Clinical Endocrinology and Metabolism, vol. 90, no. 12, pp. 6448-6453, 2005.

[35] S. P. Hye, K.-U. Lee, S. K. Young, and Y. P. Cheol, "Relationships between fasting plasma ghrelin levels and metabolic parameters in children and adolescents," Metabolism, vol. 54, no. 7, pp. 925-929, 2005.

[36] D. L. Williams, H. J. Grill, D. E. Cummings, and J. M. Kaplan, "Vagotomy dissociates short- and long-term controls of circulating ghrelin," Endocrinology, vol. 144, no. 12, pp. 5184-5187, 2003.

[37] K. Choi, S.-G. Roh, Y.-H. Hong, et al., "The role of ghrelin and growth hormone secretagogues receptor on rat adipogenesis," Endocrinology, vol. 144, no. 3, pp. 754-759, 2003.

[38] N. M. Thompson, D. A. S. Gill, R. Davies, et al., "Ghrelin and des-octanoyl ghrelin promote adipogenesis directlyin vivo by a mechanism independent of GHS-R1a," Endocrinology, vol. 145, no. 1, pp. 234-242, 2004.

[39] T. Tsubone, T. Masaki, I. Katsuragi, K. Tanaka, T. Kakuma, and H. Yoshimatsu, "Ghrelin regulates adiposity in white adipose tissue and UCP1 mRNA expression in brown adipose tissue in mice," Regulatory Peptides, vol. 130, no. 1-2, pp. 97-103, 2005.

[40] S. Ghelardoni, V. Carnicelli, S. Frascarelli, S. Ronca-Testoni, and R. Zucchi, "Ghrelin tissue distribution: comparison 
between gene and protein expression," Journal of Endocrinological Investigation, vol. 29, no. 2, pp. 115-121, 2006.

[41] M. Korbonits, S. A. Bustin, M. Kojima, et al., "The expression of the growth hormone secretagogue receptor ligand ghrelin in normal and abnormal human pituitary and other neuroendocrine tumors," Journal of Clinical Endocrinology and Metabolism, vol. 86, no. 2, pp. 881-887, 2001.

[42] M. Volante, E. Allìa, P. Gugliotta, et al., "Expression of ghrelin and of the GH secretagogue receptor by pancreatic islet cells and related endocrine tumors," Journal of Clinical Endocrinology and Metabolism, vol. 87, no. 3, pp. 1300-1308, 2002.

[43] K. K. McKee, O. C. Palyha, S. D. Feighner, et al., "Molecular analysis of rat pituitary and hypothalamic growth hormone secretagogue receptors," Molecular Endocrinology, vol. 11, no. 4, pp. 415-423, 1997.

[44] A. F. Leite-Moreira, A. Rocha-Sousa, and T. HenriquesCoelho, "Cardiac, skeletal, and smooth muscle regulation by ghrelin," Vitamins and Hormones, vol. 77, pp. 207-238, 2007.

[45] M. Papotti, C. Ghè, P. Cassoni, et al., "Growth hormone secretagogue binding sites in peripheral human tissues," Journal of Clinical Endocrinology and Metabolism, vol. 85, no. 10, pp. 3803-3807, 2000.

[46] S. Gnanapavan, B. Kola, S. A. Bustin, et al., "The tissue distribution of the mRNA of ghrelin and subtypes of its receptor, GHS-R, in humans," Journal of Clinical Endocrinology and Metabolism, vol. 87, no. 6, pp. 2988-2991, 2002.

[47] P. Cassoni, M. Papotti, C. Ghè, et al., "Identification, characterization, and biological activity of specific receptors for natural (ghrelin) and synthetic growth hormone secretagogues and analogs in human breast carcinomas and cell lines," Journal of Clinical Endocrinology and Metabolism, vol. 86, no. 4, pp. 1738-1745, 2001.

[48] M. J. Kleinz, J. J. Maguire, J. N. Skepper, and A. P. Davenport, "Functional and immunocytochemical evidence for a role of ghrelin and des-octanoyl ghrelin in the regulation of vascular tone in man," Cardiovascular Research, vol. 69, no. 1, pp. 227235, 2006.

[49] S. D. Katugampola, Z. Pallikaros, and A. P. Davenport, “[125IHis9]-ghrelin, a novel radioligand for localizing GHS orphan receptors in human and rat tissue; up-regulation of receptors with atherosclerosis," British Journal of Pharmacology, vol. 134, no. 1, pp. 143-149, 2001.

[50] G. Baldanzi, N. Filigheddu, S. Cutrupi, et al., "Ghrelin and des-acyl ghrelin inhibit cell death in cardiomyocytes and endothelial cells through ERK1/2 and PI 3-kinase/AKT," Journal of Cell Biology, vol. 159, no. 6, pp. 1029-1037, 2002.

[51] N. Nagaya, M. Uematsu, M. Kojima, et al., "Elevated circulating level of ghrelin in cachexia associated with chronic heart failure: relationships between ghrelin and anabolic/catabolic factors," Circulation, vol. 104, no. 17, pp. 2034-2038, 2001.

[52] S. Frascarelli, S. Ghelardoni, S. Ronca-Testoni, and R. Zucchi, "Effect of ghrelin and synthetic growth hormone secretagogues in normal and ischemic rat heart," Basic Research in Cardiology, vol. 98, no. 6, pp. 401-405, 2003.

[53] N. Nagaya, M. Uematsu, M. Kojima, et al., "Chronic administration of ghrelin improves left ventricular dysfunction and attenuates development of cardiac cachexia in rats with heart failure," Circulation, vol. 104, no. 12, pp. 1430-1435, 2001.

[54] N. Nagaya, M. Kojima, M. Uematsu, et al., "Hemodynamic and hormonal effects of human ghrelin in healthy volunteers," American Journal of Physiology, vol. 280, no. 5, pp. R1483R1487, 2001.
[55] N. Nagaya, J. Moriya, Y. Yasumura, et al., "Effects of ghrelin administration on left ventricular function, exercise capacity, and muscle wasting in patients with chronic heart failure," Circulation, vol. 110, no. 24, pp. 3674-3679, 2004.

[56] N. Nagaya, M. Kojima, and K. Kangawa, "Ghrelin, a novel growth hormone-releasing peptide, in the treatment of cardiopulmonary-associated cachexia," Internal Medicine, vol. 45, no. 3, pp. 127-134, 2006.

[57] D. Ashby, P. Choi, and S. Bloom, "Gut hormones and the treatment of disease cachexia," Proceedings of the Nutrition Society, vol. 67, no. 3, pp. 263-269, 2008.

[58] K. Mizia-Stec, B. Zahorska-Markiewicz, M. OlszaneckaGlinianowicz, et al., "Ghrelin as a potential blood pressure reducing factor in obese women during weight loss treatment," Endokrynologia Polska, vol. 59, no. 3, pp. 207-211, 2008.

[59] T. Soeki, I. Kishimoto, D. O. Schwenke, et al., "Ghrelin suppresses cardiac sympathetic activity and prevents early left ventricular remodeling in rats with myocardial infarction," American Journal of Physiology, vol. 294, no. 1, pp. H426H432, 2008.

[60] E. A. García and M. Korbonits, "Ghrelin and cardiovascular health," Current Opinion in Pharmacology, vol. 6, no. 2, pp. 142-147, 2006.

[61] K. E. Wiley and A. P. Davenport, "Comparison of vasodilators in human internal mammary artery: ghrelin is a potent physiological antagonist of endothelin-1," British Journal of Pharmacology, vol. 136, no. 8, pp. 1146-1152, 2002.

[62] M. Tesauro, F. Schinzari, M. Iantorno, et al., "Ghrelin improves endothelial function in patients with metabolic syndrome," Circulation, vol. 112, no. 19, pp. 2986-2992, 2005.

[63] M. Iantorno, H. Chen, J.-A. Kim, et al., "Ghrelin has novel vascular actions that mimic PI 3-kinase-dependent actions of insulin to stimulate production of NO from endothelial cells," American Journal of Physiology, vol. 292, no. 3, pp. E756-E764, 2007.

[64] M. Tesauro, F. Schinzari, V. Rovella, et al., "Ghrelin restores the endothelin $1 /$ nitric oxide balance in patients with obesityrelated metabolic syndrome," Hypertension, vol. 54, no. 5, pp. 995-1000, 2009.

[65] J. Pettersson, G. Muccioli, R. Granata, et al., "Natural (ghrelin) and synthetic (hexarelin) GH secretagogues stimulate H9c2 cardiomyocyte cell proliferation," Journal of Endocrinology, vol. 175, no. 1, pp. 201-209, 2002.

[66] M. J. Iglesias, R. Piñeiro, M. Blanco, et al., "Growth hormone releasing peptide (ghrelin) is synthesized and secreted by cardiomyocytes," Cardiovascular Research, vol. 62, no. 3, pp. 481-488, 2004.

[67] J. Isgaard, A. Barlind, and I. Johansson, "Cardiovascular effects of ghrelin and growth hormone secretagogues," Cardiovascular and Hematological Disorders: Drug Targets, vol. 8, no. 2, pp. 133-137, 2008.

[68] B. Kola, E. Hubina, S. A. Tucci, et al., "Cannabinoids and ghrelin have both central and peripheral metabolic and cardiac effects via AMP-activated protein kinase," Journal of Biological Chemistry, vol. 280, no. 26, pp. 25196-25201, 2005.

[69] V. D. Dixit, E. M. Schaffer, R. S. Pyle, et al., "Ghrelin inhibits leptin- and activation-induced proinflammatory cytokine expression by human monocytes and T cells," Journal of Clinical Investigation, vol. 114, no. 1, pp. 57-66, 2004.

[70] M. Granado, T. Priego, A. I. Martín, M. Villanúa, and A. López-Calderón, "Anti-inflammatory effect of the ghrelin agonist growth hormone-releasing peptide-2 (GHRP-2) in arthritic rats," American Journal of Physiology, vol. 288, no. 3, pp. E486-E492, 2005. 
[71] M. D. DeBoer, X. Zhu, P. R. Levasseur, et al., "Ghrelin treatment of chronic kidney disease: improvements in lean body mass and cytokine profile," Endocrinology, vol. 149, no. 2, pp. 827-835, 2008.

[72] W. G. Li, D. Gavrila, X. Liu, et al., "Ghrelin inhibits proinflammatory responses and nuclear factor- $\kappa \mathrm{B}$ activation in human endothelial cells," Circulation, vol. 109, no. 18, pp. 2221-2226, 2004. 

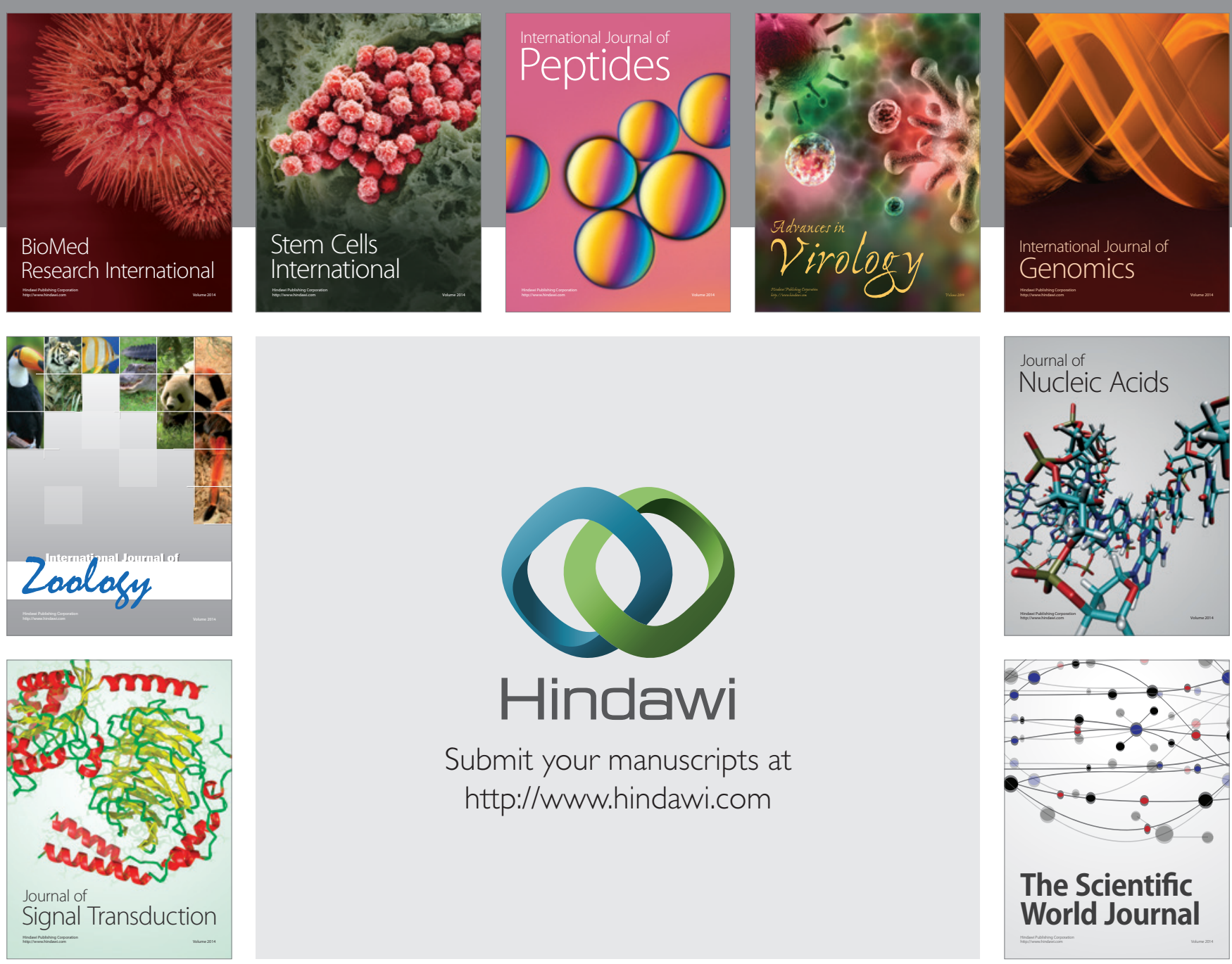

Submit your manuscripts at

http://www.hindawi.com
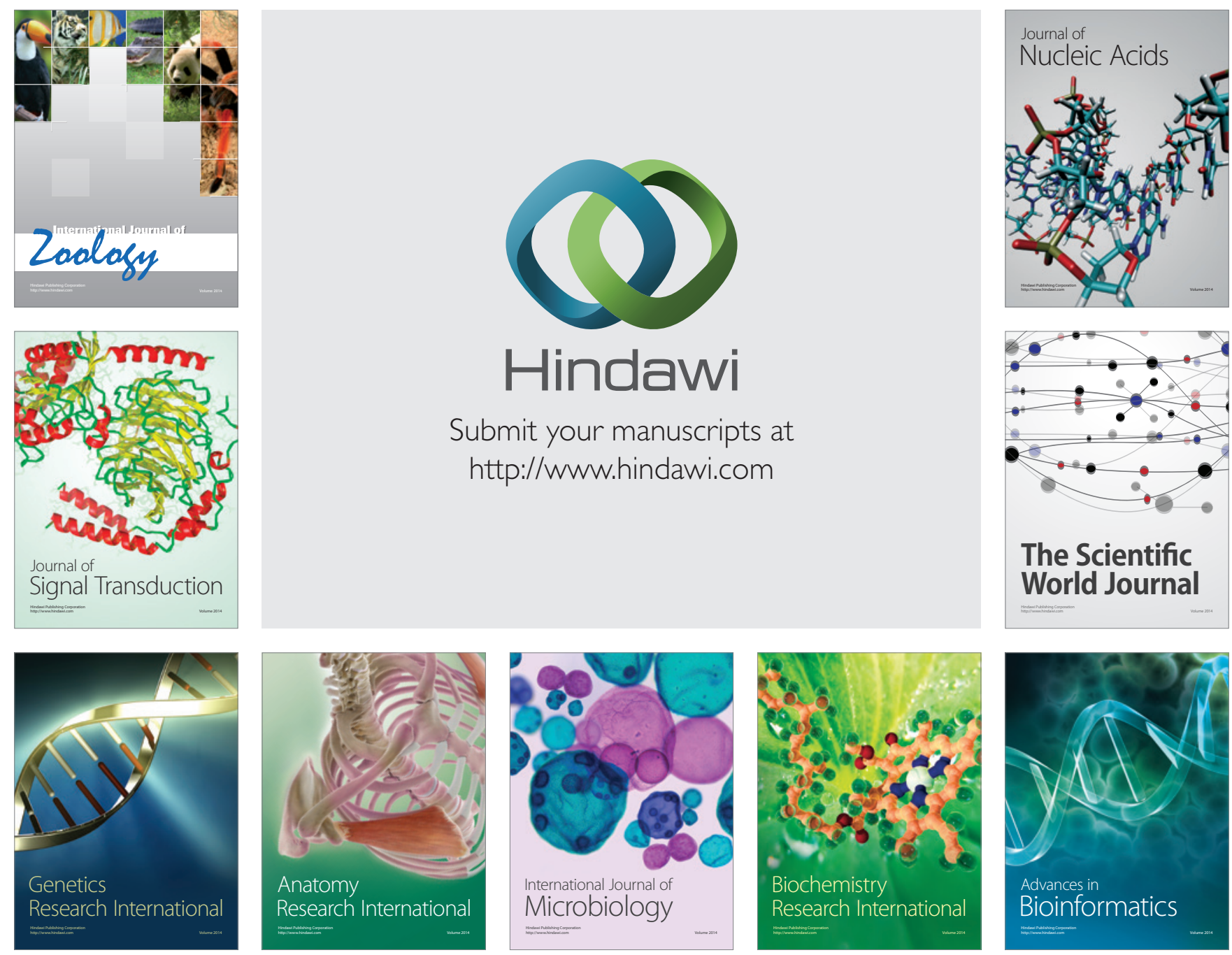

The Scientific World Journal
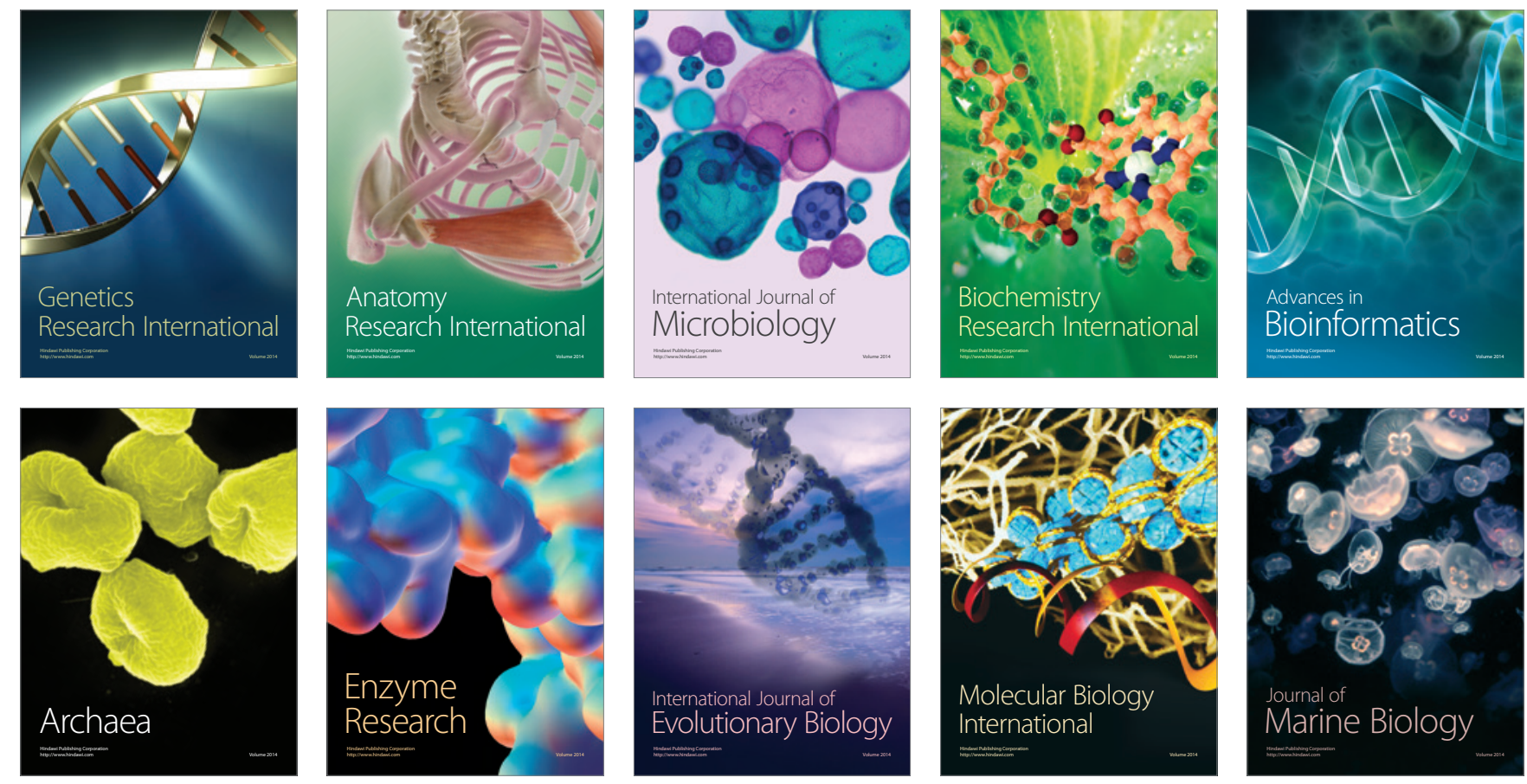